\title{
Erk 1,2 phosphorylates p27 Kip1: Functional evidence for a role in high glucose-induced hypertrophy of mesangial cells
}

\author{
G. Wolf ${ }^{1}$, R. Reinking ${ }^{1}$, G. Zahner ${ }^{1}$, R. A. K. Stahl ${ }^{1}$, S. J. Shankland ${ }^{2}$ \\ ${ }^{1}$ Division of Nephrology and Osteology, Department of Medicine, University of Hamburg, University Hospital Eppendorf, \\ Hamburg, Germany \\ ${ }^{2}$ Division of Nephrology, Department of Medicine, University of Washington, Seattle, USA
}

\begin{abstract}
Aims/hypothesis. Mesangial cell hypertrophy is one of the earliest morphological abnormalities of diabetic nephropathy. We have previously shown that high glucose induces p27 Kip1 by a post-transcriptional mechanism and that mesangial cell hypertrophy depends on $\mathrm{G}_{1}$-phase arrest mediated by this CDK-inhibitor. However, it remains poorly understood how high glucose stimulates p27Kip1 expression in mesangial cells.

Methods. Mesangial cells were isolated from p27Kip1 $+/+$ and -/- mice and characterized by light microscopy and immunohistochemistry. It was tested by Western blotting and autoradiography whether high glucose medium activates Erk 1,2 and whether this activation phosphorylates $\mathrm{p} 27 \mathrm{Kip} 1$. The three consensus phosphorylation sites of p27Kip1 were mutated and these constructs were expressed in $\mathrm{p} 27^{\mathrm{Kip} 1}-/$ - mesangial cells. Hypertrophy was assessed by different methods.
\end{abstract}

Results. High glucose stimulates phosphorylation of MAP kinases Erk 1,2 in p27 $\mathrm{Kip}^{1}+/+$ and -/- mesangial cells. Activation of Erk 1,2 leads to phosphorylation of p27Kip1 in vitro and in vivo. Mutations of serine ${ }^{10}$ or threonine ${ }^{187}$ still supported high glucose-induced hypertrophy. In contrast, a mutation of serine ${ }^{178}$ converted the hypertrophic response into a proliferative phenotype. Mutation of serine ${ }^{178}$ leads to the attenuated expression of $\mathrm{p} 27^{\mathrm{Kip} 1}$ protein in the presence of high glucose.

Conclusions/interpretation. Our study shows that high glucose stimulates Erk 1,2 that phosphorylate p27Kip1 at serine ${ }^{178}$ increasing its expression. This is an important molecular mechanism of high glucose-induced hypertrophy of mesangial cells. [Diabetologia (2003) 46:1090-1099]

Keywords p27, cyclin dependent kinase, hypertrophy, glucose, mesangial cells.
Glomerular hypertrophy is one of the earliest morphologic changes of Type 1 and 2 diabetic nephropathy, and is principally due to mesangial cell growth $[1,2]$. Experimental and clinical studies show that mesangial hypertrophy contributes to the subsequent develop-

Received: 11 December 2002 / Revised: 25 April 2003

Published online: 10 July 2003

(C) Springer-Verlag 2003

Corresponding author: Dr. G. Wolf, Division of Nephrology and Osteology, Department of Medicine, University of Hamburg, University Hospital Eppendorf, Pavilion 26, Martinistr. 52, 20246 Hamburg, Germany

E-mail: Wolf@uke.uni-hamburg.de ment of glomerulosclerosis and decline in renal function $[3,4,5]$. Thus, delineating the mechanisms underlying mesangial hypertrophy are essential to the design of potential interventions in diabetic nephropathy. We and others have previously shown that cultured mesangial cells exposed to high glucose undergo hypertrophy after $48 \mathrm{~h}$ of incubation $[6,7,9]$. Cell cycle analysis showed that cells arrest in the $G_{1}$ phase of the cell cycle following prolonged exposure to high glucose-containing medium [6], supporting the idea that the cell cycle plays a critical role in diabetic renal disease.

The cell cycle is positively controlled by cyclins and partner cyclin-dependent kinases (CDK), and is 
negatively governed by CDK inhibitors. We have recently shown that glucose-induced $\mathrm{G}_{1}$ arrest was associated with an up-regulation of the CDK inhibitor, p27Kip1 protein, but not mRNA expression [10]. In vivo studies also showed increased mesangial p27Kip1 in models of experimental diabetic nephropathy [11]. A functional role for $\mathrm{p} 27^{\mathrm{Kip} 1}$ in mediating mesangial hypertrophy was proven by showing that in contrast to p27Kip1 wild-type mesangial cells $(+/+)$, high glucose failed to induce hypertrophy in p27 Kip1 $-/$ - mesangial cells. Indeed, high glucose facilitated cell cycle progression in p27Kip1-/- cells, but caused cell cycle arrest in p $27^{\mathrm{Kip} 1}+/+$ cells [12]. Finally, reconstituting p27 Kip1 with an inducible vector system restored high glucose-mediated hypertrophic phenotype in p27Kip1 $-/-$ cells [12]. These results show that $\mathrm{p} 27 \mathrm{Kip} 1$ is functionally required for glucose-induced cell cycle arrest and hypertrophy [12].

The mechanisms whereby high glucose increases p27 Kip1 protein expression by post-transcriptional mechanisms has not been well elucidated. Studies have shown that MAP kinases (Erk 1,2) are activated in diabetic nephropathy, and that inhibition of MAP kinase activation inhibits mesangial hypertrophy [13, 14]. Accordingly, we tested the hypothesis that Erk 1,2 phosphorylates $\mathrm{p} 27^{\mathrm{Kip} 1}$ in vitro. In this study we identified specific phosphorylation sites in p27Kip1 that are phosphorylated by Erk 1,2, and we utilized mutational analysis to show which of these is required for glucose-induced hypertrophy of mesangial cells.

\section{Material and methods}

Cell culture and characterization of mouse mesangial cells. Mesangial cells (MCs) from litter mate p27Kip1 +/+ and p27Kip1 -/- mice were originally isolated by differential sieving [12]. MCs were grown in Dulbecco's Modified Eagle's Medium (DMEM; Gibco-BRL, Eggenstein, Germany) containing $100 \mathrm{mg} / \mathrm{dl}(5.5 \mathrm{mmol} / \mathrm{l}) \mathrm{D}$-glucose supplemented with $10 \%$ foetal calf serum (FCS), $100 \mathrm{U} / \mathrm{ml}$ penicillin, $100 \mu \mathrm{g} / \mathrm{ml}$ streptomycin, and $2 \mathrm{mmol} / \mathrm{l}$ glutamine. They were cultured at $37^{\circ} \mathrm{C}$ in $5 \% \mathrm{CO}_{2}$, and passaged every 4 to 5 days. Experiments were carried out on passage 15 to 30 cells.

Cells of passage 20 were again characterized for this study by light microscopy and immunohistochemistry according to published criteria $[13,14]$. Cells were fixed in methanol at $20^{\circ} \mathrm{C}$ for $20 \mathrm{~min}$ and were then washed in phosphate-buffered saline (PBS). Primary antibodies were diluted in PBS containing $1 \% \mathrm{BSA}$. All primary antibodies were incubated on the cells at $4^{\circ} \mathrm{C}$ overnight. The following primary antibodies were used: mouse anti-smooth muscle actin 1:500 (Sigma, Deisenhofen, Germany); mouse anti-desmin 1:100 (Research Diagnostics, Flanders, N.J., USA); mouse-anti-vimentin 1:50 (Dako, Carpenteria, Calif., USA); mouse anti-myosin 1:100 (Dako); goat anti-collagen I 1:200 (Southern Biotechnology Associates, Birmingham, Ala., USA); mouse anti-collagen IV 1:50 (Dako);and rabbit anti-AT1 receptor 1:50 (Santa Cruz Biotechnology, Santa Cruz, Calif., USA). The unbound primary antibody was washed away and the following secondaries were applied: biotinylated-horse-anti-mouse IgG 1:500 (Vector Labs, Burlingame, Calif., USA), biotinylated-goat-anti-rabbit
IgG 1:200 (Vector Labs), and biotinylated-rabbit-anti-goat IgG 1:200 (Zymed, San Francisco, Calif., USA); and incubated at room temperature for $30 \mathrm{~min}$. Antibodies were visualized using streptavidin-conjugated with Alexa Fluor. 594, 1:200 (Molecular Probes, Eugene, Ore., USA). Images of stained cells were taken on a Leica DMIL inverted microscope (Bartels \& Atout, Bellevue, Wash., USA) using a digital CoolSNAPpro camera (Media Cybernetics, Silver Springs, Md., USA).

Leucine Incorporation. The incorporation of $3[\mathrm{H}]$ leucine was used to assess de novo protein synthesis as previously reported $[6,12]$. Briefly, cells were plated $\left(10^{5}\right.$ per well $)$ in 24 -well plates, and were made quiescent for $12 \mathrm{~h}$ in serum-free media with a normal concentration of glucose $(5.5 \mathrm{mmol} / \mathrm{l})$. After an additional $12 \mathrm{~h}$, the medium was replaced with either normal glucose or high glucose $(450 \mathrm{mg} / \mathrm{dl}, 25 \mathrm{mmol} / \mathrm{l})$ for $48 \mathrm{~h}$. $18.5 \times 10^{4} \mathrm{~Bq}$ of $3[\mathrm{H}]$ leucine $\left(5.25 \times 10^{12} \mathrm{~Bq} / \mathrm{mmol}\right.$, AmershamPharmacia Biotech, Freiburg, Germany) was added to each well for the last $12 \mathrm{~h}$ of the experiment. At the end of the incubation period, MCs were washed twice in ice-cold PBS and proteins were subsequently precipitated with ice-cold $10 \%$ trichloroacetic acid. After redissolving the precipitates in $0.5 \mathrm{~mol} / \mathrm{l} \mathrm{NaOH}$ containing $0.1 \%$ Triton X-100, $5 \mathrm{ml}$ scintillation cocktail (Roth, Karlsruhe, Germany) was added, and radioactivity was measured by liquid scintillation spectroscopy. $3[\mathrm{H}]$ leucine incorporation experiments were repeated five times with duplicate measurements for each experiment.

Thymidine Incorporation. The incorporation of ${ }^{3}[\mathrm{H}]$ thymidine into DNA was used to measure proliferation [6, 12]. Cells $\left(10^{4}\right.$ cells per well) were transferred to a 96-well microtitre plate. After incubation for $12 \mathrm{~h}$ in normal glucose medium, MCs were subsequently grown for another $48 \mathrm{~h}$ in either normal or high glucose. Cells were pulsed with $3.7 \times 10^{4} \mathrm{~Bq}^{3}[\mathrm{H}]$ thymidine $\left(18.5 \times 10^{10} \mathrm{~Bq} / \mathrm{mmol}\right.$, Amersham) during the last $6 \mathrm{~h}$ of culture. At the end of the incubation period, MCs were washed in PBS, trypsinized for $10 \mathrm{~min}$ a $37^{\circ} \mathrm{C}$, and finally collected on glass-fibre paper with an automatic cell harvester. Radioactivity of dry filters was measured by liquid scintillation spectroscopy. ${ }^{3}[\mathrm{H}]$ thymidine experiments were independently carried out four times with triplicate measurements.

Total protein to cell count ratio. The ratio of total protein content to cell number is another well established measure of cellular hypertrophy [12]. To measure this ratio, $10^{5} \mathrm{p} 27^{\mathrm{Kip} 1}+/+$ and $\mathrm{p} 27^{\mathrm{Kip} 1}-\mathrm{l}$ - MCs were seeded into each well of a six-well plate and were synchronized into quiescence for $12 \mathrm{~h}$ in serumfree medium containing a normal glucose concentration. p27 Kip1 -/- MCs were transfected with the various constructs and cultured in either normal or high glucose containing medium. In selected experiments, p27Kip1 +/+ MCs were also exposed to the specific MAP kinase kinase 1 (MEK1) inhibitor PD98059 [2-(2'-amino-3'-methoxyphenyl)oxanaphthalen-4one] (10-5 mol/l, Calbiochem-Novabiochem, Bad Soden, Germany). After incubation for another $48 \mathrm{~h}$, cells were trypsinized, scraped off the plate with a rubber policeman, and washed twice in PBS. A small aliquot of cells were used for cell counting in a Fuchs-Rosenthal chamber after re-suspension in PBS to calculate the cell number/protein ratio. The remaining cells were lysed in $0.5 \mathrm{~mol} / \mathrm{l} \mathrm{NaOH}$, and total protein content was measured by a modified Lowry method. Total protein content was expressed as $\mu \mathrm{g}$ protein per $10^{3}$ cells. These experiments were independently carried out five times.

Cell cycle analysis. In order to carry out cell cycle analysis, cells were trypsinized, washed in ice-cold PBS, and stained for $15 \mathrm{~min}$ with $50 \mu \mathrm{g} / \mathrm{ml}$ propidium iodide in staining buffer 
( $0.1 \%$ citrate, $0.1 \%$ Triton X100, $50 \mu \mathrm{g} / \mathrm{ml}$ RNAse). Cells were analyzed with FACSCalibur (Becton Dickinson, Franklin Lakes, N.J., USA) using CellQuest software (Becton Dickinson). Cell cycle analysis was done with the ModFit LT V 2.0 program (Verity Software House, Topsham, Me., USA). Cell cycle analysis was carried out separately on two occasions. In addition to cell cycle analysis, forward cell scatter was used to measure cell size. Microbead standards (Bangs Laboratories, Fishers, Ind., USA) with defined sizes $[4.3,6.8,7.9,8.7$, $10.8 \times 10^{-6} \mathrm{~m}$ diameter) were analyzed in parallel. The peak channel number of each microbead was measured and plotted against bead diameter. A linear relationship was obtained and cell diameters were calculated from this graph. Forward cell scatter experiments were independently done three times (independent stimulation and transfection, if appropriate).

Western blot analysis. MCs were grown in $50 \mathrm{ml}$ flasks in DMEM with $10 \%$ FCS to 70 to $80 \%$ confluence, at which time the medium was changed to serum-free DMEM for $24 \mathrm{~h}$ and cells were subsequently grown in normal or high glucose. At the end of the stimulation period, cells were washed with PBS and lysed with $100 \mu \mathrm{l}$ lysis buffer (2\% SDS, $60 \mathrm{mmol} / \mathrm{l}$ Tris$\mathrm{HCl}, \mathrm{pH} 6.8$ ), and the lysates were cleared by centrifugation. Samples of $80 \mu \mathrm{g}$ protein (measured by a modification of the Lowry method) were denatured by the addition of 5\% glycerol, $5 \%$ mercapthoethanol and $0.03 \%$ bromophenol blue, and boiled for $10 \mathrm{~min}$. After centrifugation, the supernatants were loaded on a $12 \%$ SDS-polyacrylamide gel. Low molecular weight marker (Rainbow-marker, Amersham) served as the molecular weight standard. After electrophoresis, proteins were electroblotted semi-dry for $1 \mathrm{~h}$ at $0.8 \mathrm{~mA} / \mathrm{cm}^{2}$ to a PVDF membrane (Hybond P, Amersham). Selected membranes were stained with Ponceau S (Sigma) to ensure equal loading and transfer of proteins. The blots were blocked in 5\% non-fat dry milk in PBS containing $0.1 \%$ Tween 20 for $1 \mathrm{~h}$ at room temperature. The following antibodies were all used in a 1:1000 dilution: a mouse monoclonal anti-p27Kip1 antibody (BD Bioscience, Heidelberg, Germany), a rabbit polyclonal anti-Erk 1,2 antibody, and a monoclonal mouse phospho-specific Erk 1,2 (Thr202/Tyr204) antibody (all from New England Biolabs; Beverly, Mass., USA). Incubation was carried out for $1 \mathrm{~h}$ at room temperature. The blots were then washed once for 15 min and twice for 5 min in PBS containing $0.1 \%$ Tween 20. After incubation with an appropriate secondary antibody coupled to horseradish peroxidase, blots were washed again for 25 min and the detection was carried out using the ECL system (Amersham). Selected blots were washed and reprobed with an antibody against $\beta$-actin (Sigma) to control for small variations in protein loading and transfer. Exposed films were scanned with Fluor-S multi-imager (Bio-Rad Laboratories, Hercules, USA), and data were analyzed with the computer program Multi-Analyst from Bio-Rad. Signal intensities in control lanes were arbitrarily assigned a value of 1.00 . Western blots were repeated three times.

Gene construct and transfections. A full length mouse p27Kip1 cDNA was cloned into Bluescript (Stratagene, Heidelberg, Germany). The following putative phosphorylation sites for Erk 1,2 were mutated using standard PCR techniques: serine ${ }^{10}$ to arginine, serine ${ }^{178}$ to alanine, and threonine ${ }^{187}$ to alanine. Wild-type and mutated cDNAs were cloned into the pIND vector (Invitrogen, Leek, Netherlands) and were sequenced to confirm correct orientation and the presence or absence of mutations. The expression plasmid pIND contains five modified ecdysone response elements upstream of a minimal heat shock promoter allowing inducible expression. For transient transfections, $10^{5}$ p27Kip1 $-/$ MCs were first grown in serum-free medium for $24 \mathrm{~h}$ and then co-transfected with $10 \mu \mathrm{g}$ of pIN$\mathrm{Dp} 27^{\mathrm{Kip} 1}$ and $10 \mu \mathrm{g}$ of the plasmid $\mathrm{pVgRXR}$ (Invitrogen) encoding subunits of the ecdysone receptor using lipofectin (Gibco-BRL) [12]. Cells were then incubated for $48 \mathrm{~h}$ in either normal or high glucose in the presence or absence of the inducer muristone $(1 \mu \mathrm{g} / \mathrm{ml})$. Hypertrophy, proliferation, and cell cycle analysis were carried out after $48 \mathrm{~h}$ of stimulation.

Expression of recombinant p27Kipl and phosphorylation assays. A full length mouse p27Kip1 cDNA with a polyhistidine (6×His) tag cloned into pcDNA 3 was a gift of M. Eilers, University of Marburg, Germany [17]. Recombinant p27Kip1 protein was expressed in E.coli and isolated by affinity chromatography using the TALON system (Clontech, Heidelberg, Germany) according to the manufacturer's recommendations. $\mathrm{p} 27^{\mathrm{Kip} 1}$ protein was eluted in the second and third fraction. SDS-polyacrylamide electrophoresis and Western blot analysis with a monoclonal anti-p27Kip1 antibody revealed the presence of a single band (data not shown). Recombinant p27Kip1 $(5 \mu \mathrm{g})$ was incubated with $2 \mu \mathrm{g}$ of activated recombinant rat MAP kinase (Erk 2, activity >600 units/ $\mu$ g protein; Calbiochem-Novabiochem, Bad Soden, Germany), $1 \mu 10 \mathrm{mmol} / \mathrm{l}$ ATP, and $1 \mu \mathrm{l}$ adenosine $5^{\prime}-\left[\gamma_{-}{ }^{32} \mathrm{P}\right]$ triphosphate $(>5000 \mathrm{Ci} / \mathrm{mmol}$; Amersham) in kinase buffer $(25 \mathrm{mmol} / \mathrm{l}$ Tris- $\mathrm{HCl}, \mathrm{pH} 7.5 ; 2 \mathrm{mmol} / \mathrm{l}$ dithiothreitol, $0.1 \mathrm{mmol} / 1 \mathrm{Na}_{3} \mathrm{VO}_{4}, 10 \mathrm{mmol} / 1 \mathrm{MgCl}_{2}$ ) for $30 \mathrm{~min}$ at $30^{\circ} \mathrm{C}$. The product was separated on a $12 \%$ SDS-polyacrylamide gel and autoradiography was carried out for 4 days. Radioactive bands were cut out of the gel, treated with $50 \mathrm{mmol} / \mathrm{l}$ ammonium bicarbonate and proteins were precipitated with trichloroacetic acid. After resuspension, proteolyses was done with $6 \mathrm{~N} \mathrm{HCl}$ for $60 \mathrm{~min}$ at $110^{\circ} \mathrm{C}$. Electrophoresis was carried out on thin-layer cellulose plates using a Hunter thin layer peptide mapping electrophoresis system [18]. Cold phosphoamino acids (tyrosine, serine, threonine from Sigma) were run together with the sample and served as standards [18]. Bands were visualized with ninhydrin following electrophoresis, and autoradiography of the cellulose plate was then carried out. Phosphoamino acid mapping experiments were done independently on two occasions.

To test whether in vivo activated Erk 1,2 could phosphorylate recombinant $\mathrm{p} 27^{\mathrm{Kip} 1}$, wild-type $\left(\mathrm{p} 27^{\mathrm{Kip} 1}+/+\right)$ MCs were exposed for $10 \mathrm{~min}$ or $18 \mathrm{~h}$ in either normal or high glucose serum-free DMEM. Some cells were also treated with $10^{-5} \mathrm{~mol} / \mathrm{l}$ PD98059. At the end of the incubation, total Erk 1,2 was immunoprecipitated as described above. After extensive washing, immunoprecipitated Erk 1,2 was incubated with recombinant $\mathrm{p} 27^{\mathrm{Kip} 1}$ and in vitro phosphorylation was measured.

Statistical analysis. All values are shown as means \pm SEM. Statistical significance among multiple groups was tested with non-parametric Kruskal-Wallis test. Individual groups were then tested using the Wilcoxon-Mann-Whitney test. A $p$ value of less than 0.05 was considered statistically significant.

\section{Results}

Characterization of p27Kip1 +/+ and-/- mouse MCs. Mouse MCs were again characterized for this study. p27Kip1 +/+ and -/- MCs had a "stellate" appearance, overlapped one another and had many processes by light-microscopy (Fig. 1A). They did not grow in the "cobblestone" pattern of glomerular endothelial and epithelial cell types, also they did not form swirls upon confluence as fibroblasts do. p27 Kip1 -/- MCs 


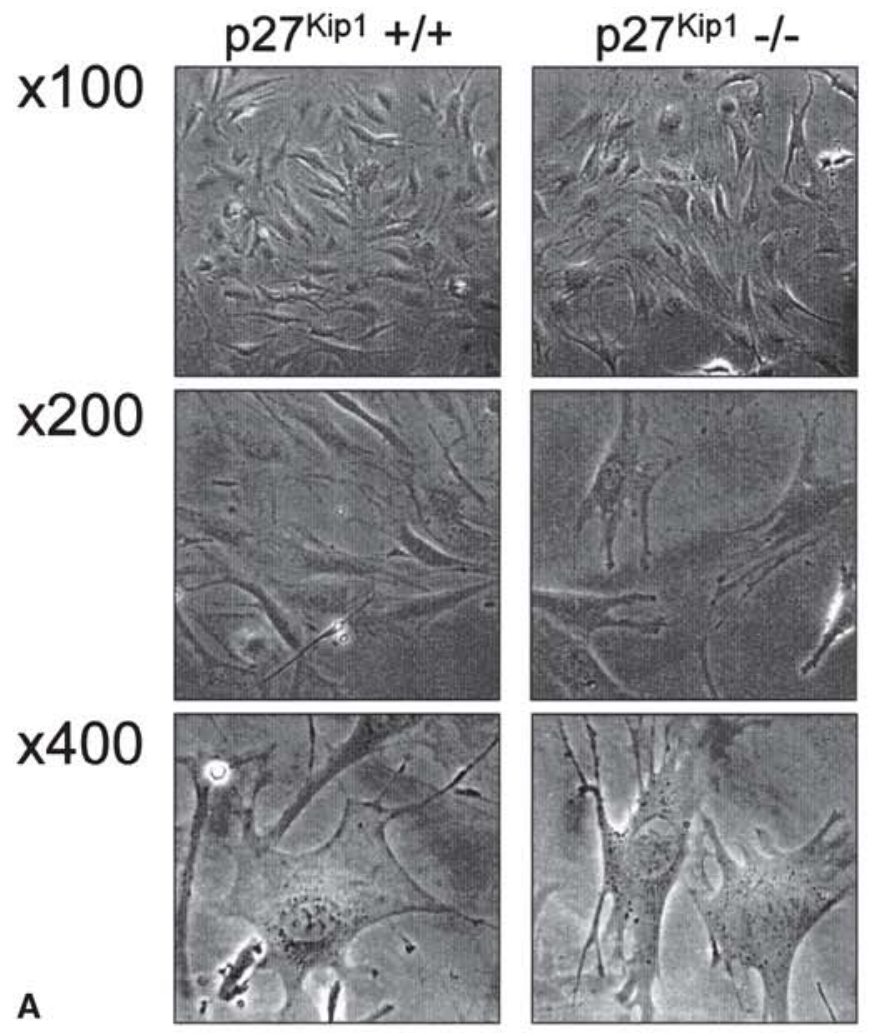

stained strongly positive for $\alpha$-smooth muscle actin and, to a lesser extent, positive for the cytoskeletal filaments desmin and vimentin (Fig. 1B). Staining MCs with antibody recognizing collagen type I showed a typical intracellular staining pattern whereas collagen type IV was mainly localized to the basement membrane (Fig. 1B). MCs also expressed angiotensin II receptors of the AT1 type. p27Kip1 +/+ MCs showed exactly the same staining pattern (data not shown). Taken together, these findings clearly indicate that our cells were of mesangial origin.

Fig. 1A, B. Characterization of mouse mesangial cells. (A) p27Kip1 +/+ and -/- MCs grow in a "stellate" pattern and exhibited many processes. Furthermore, immunohistochemistry exemplarily shown for $\mathrm{p} 2 \mathrm{~K}_{\mathrm{Kip} 1}-\mathrm{l}-\mathrm{MCs}$ revealed a strong postive staining for $\alpha$-smooth muscle (MC) actin, and a lesser positive staining pattern for the cytoskeletal filaments vimentin and desmin (B). Moreover, an antibody against collagen type I stained MCs in a typical intracellular staining pattern whereas collagen type IV was mainly localized to the basement membrane (B). MCs also expressed angiotensin II receptors of the AT1 type whereas negative controls without primary antibody revealed no specific staining. p27Kip1 $\pm / \pm$ MCs revealed exactly the same staining pattern (data not shown)
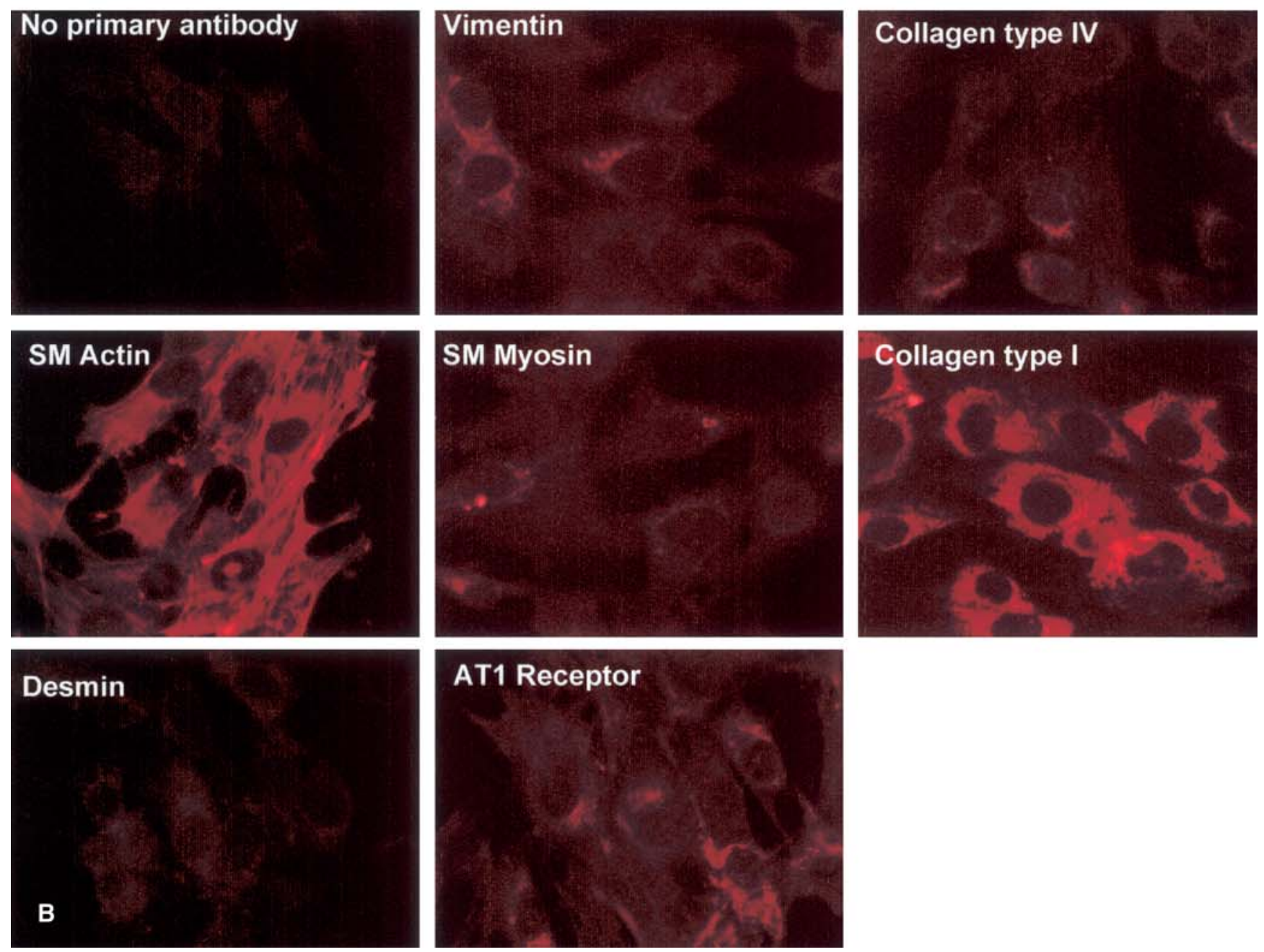
A
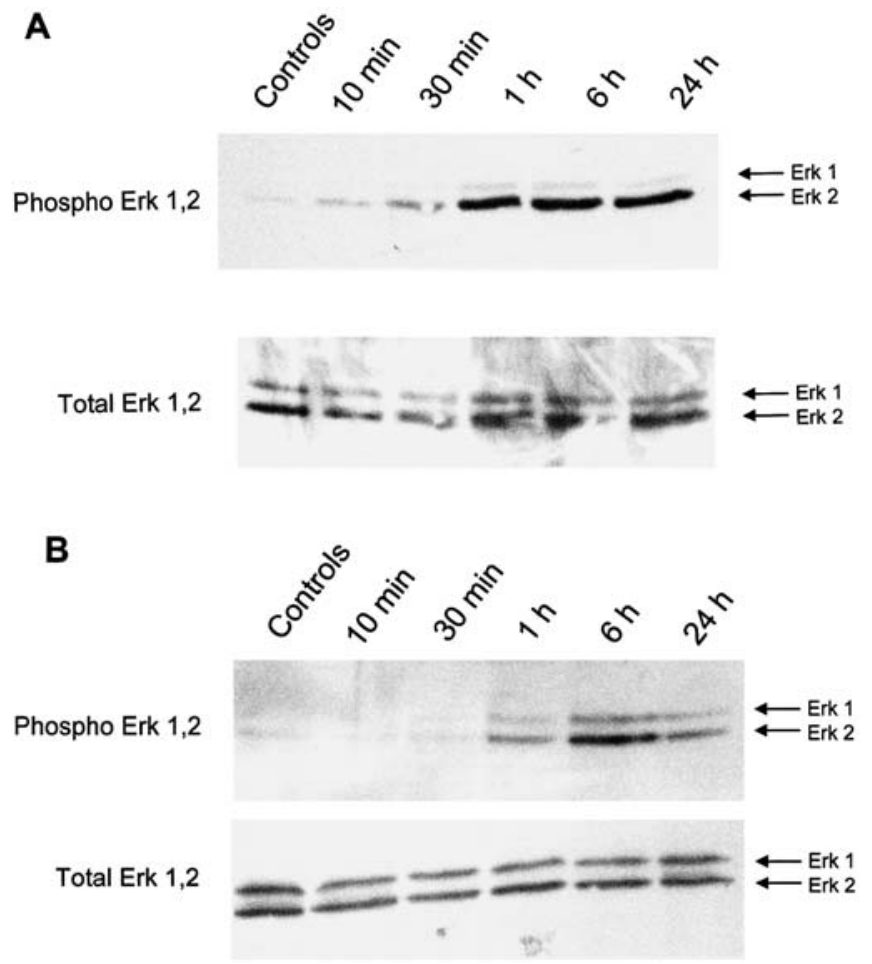

Fig. 2A, B. Western blot for Erk 1,2. Incubation of p27Kip1 $+/+$ (A) and p27Kip1 -/- (B) mesangial cells in high glucose (450 mg/dl, $25 \mathrm{mmol} / \mathrm{l})$ containing medium induced after $6 \mathrm{~h}$ phosphorylation of Erk 1,2. Phosphorylation was more pronounced for Erk 2 compared to Erk 1. Phosphorylation of Erk 1,2 occurred earlier and was more sustained in p27Kip1 -/cells. The Western blot was reprobed with an antibody against total Erk 1,2 indicating that total amount of Erk 1,2 did not change. This blot is representative of three independent experiments with qualitatively similar results

High glucose mediates Erk 1,2 activation and hypertrophy. To test the hypothesis that the post-transcriptional increase in p27Kip1 induced by high glucose requires MAPK activation, we began by measuring ERK1,2 activity. Western blots using a phospho-specific anti-Erk1,2 antibody showed phosphorylation of Erk 1,2 after $6 \mathrm{~h}$ exposure of high glucose medium in p27Kip1 +/+ and -/- MCs (Fig. 2A,B). Re-probing the Western blot with an antibody to total Erk 1,2 showed equal protein loading.

To test whether inhibition of Erk 1,2 modulates high glucose-induced hypertrophy, p27 Kip1 +/+ MC were exposed to high glucose serum-free medium in the absence or presence of the MEK1 inhibitor PD98059. Total protein per cell number, a well-established parameter of hypertrophy, was measured. As predicted, exposing mesangial cells to high glucose for $48 \mathrm{~h}$ induced hypertrophy. However, co-incubation with $10^{-5} \mathrm{~mol} / \mathrm{l}$ PD98059 prevented high glucose-induced hypertrophy (normal glucose:1.37 \pm 0.06 , normal glucose + PD98059:1.42 \pm 0.14 , high glucose: $1.74 \pm 0.05^{* *}$, high glucose + PD98059:1.51 $\pm 0.08 \mu \mathrm{g}$ protein $/ 10^{3}$ cells; $* * p<0.01$ vs normal glucose, $n=6$ ).
MAP kinase phosphorylates p27Kip1. As we showed that an increase in $\mathrm{p} 27^{\mathrm{Kip} 1}$ expression is necessary for glucose-induced hypertrophy of mesangial cells [12] we tested whether Erk 2 directly phosphorylates p27Kip1. This isoform was selected because the increase in Erk 2 was more pronounced than Erk 1 in the presence of high glucose (Fig. 2A,B). Exogenous activated Erk 2 enzyme phosphorylated recombinant mouse p27 Kip1 in vitro (Fig. 3A). Amino acid mapping using two-dimensional thin layer electrophoresis showed that serine and threonine, but not tyrosine residues, are phosphorylated by MAP kinase (Fig. 3B).

In order to investigate whether high glucose mediated activation of Erk 1,2 phosphorylate p27 Kip1 in vitro, MAP kinases were immunoprecipitated from cells grown in high glucose with an antibody against total Erk 1,2 and immunoprecipitates were used for an in vitro phosphorylation assay of recombinant p27Kip1. Immunoprecipitated complexes containing Erk 1,2 from MCs grown for $18 \mathrm{~h}$, but not for $10 \mathrm{~min}$, in high glucose phosphorylated recombinant p27 Kip1 (Fig. 3C). In vitro phosphorylation was prevented when Erk 1,2 was precipitated from cells grown in high glucose medium in the presence of PD98059 (Fig. 3C).

Mutation of serine178 prevents the high glucoseinduced expression of p27Kipl. The $\mathrm{p} 27_{\mathrm{Kip} 1}$ protein contains three consensus sites for MAP kinaseinduced phosphorylation (serine ${ }^{10}$, serine ${ }^{178}$, and threonine ${ }^{187}$ ). These amino acids were individually mutated and cloned into an ecdysone-inducible vector system.

p27Kip1 - / cells were transfected with individual mutant cDNAs and the plasmid pVgRXR encoding subunits of the ecdysone receptor. Transfected cells were exposed to either normal or high glucose for $48 \mathrm{~h}$ in the presence of $1 \mu \mathrm{g} / \mathrm{ml}$ muristone, which induced expression. Western blot analysis showed that there was a similar increase in $\mathrm{p} 27^{\mathrm{Kip} 1}$ expression in p27 Kip1 +/+ cells and in p27 Kip1 -/- MCs transfected with the serine ${ }^{10}$ and threonine ${ }^{187}$ mutant p27 Kip1 when exposed to high glucose. In contrast glucose did not increase p27Kip1 levels in p27 Kip1_/- cells transfected with the serine ${ }^{178}$ mutant construct (Fig. 4A; wildtype normal glucose:1.00, wild-type high glucose: $3.34 \pm 0.7^{*}$, serine ${ }^{10}$ mutant normal glucose: 1.00 , serine ${ }^{10}$ mutant high glucose: $2.5 \pm 0.3^{*}$, serine ${ }^{178}$ mutant normal glucose:1.00, serine ${ }^{178}$ mutant high glucose:0.79 \pm 0.6 , threonine ${ }^{187}$ mutant normal glucose:1.00, threonine ${ }^{187}$ mutant high glucose: $2.06 \pm 0.6^{*}$ relative $\mathrm{p} 27^{\mathrm{Kip} 1}$ expression normalized to $\beta$ actin, ${ }^{*} p<0.05$ versus normal glucose, $n=3$ ). These results show that the increase in $\mathrm{p} 27^{\mathrm{Kip} 1}$ by glucose specifically requires phosphorylation on serine ${ }^{178}$.

Functional role of serine 178 mutation of p27Kipl in high glucose-induced hypertrophy. We have previously shown [12] that high glucose inhibits proliferation 
A

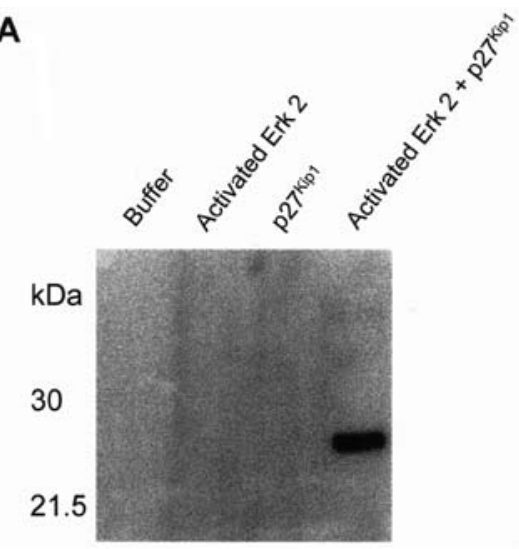

B

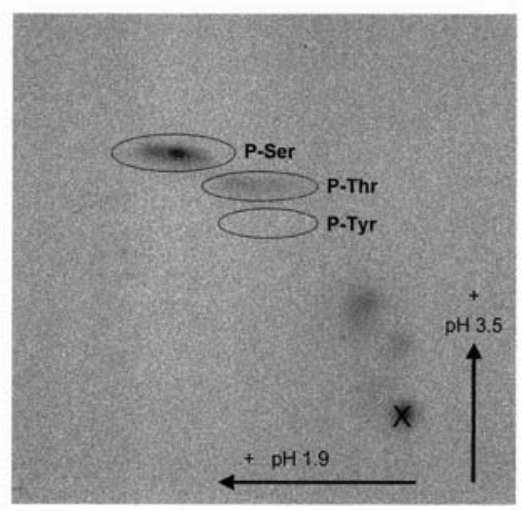

C

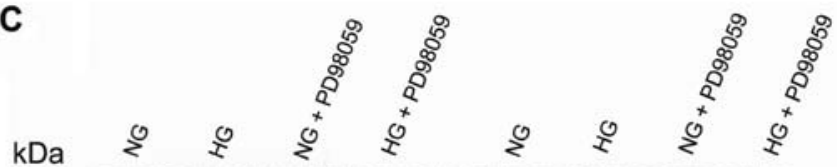

30

21.5

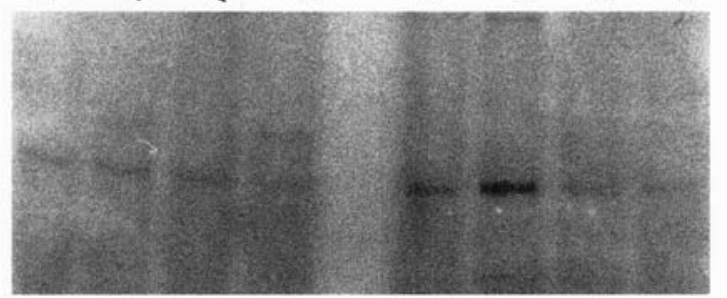

10 Minutes

Fig. 3A-C. MAP kinase induced phosphorylation of p27Kip1. (A) Recombinant $\mathrm{p} 27^{\mathrm{Kip} 1}$ was expressed and incubated with activated phosphorylated Erk 2 in the presence of $\left[\gamma^{-32} \mathrm{P}\right]$ ATP in kinase buffer. Proteins were separated by SDS-polyacrylamide electrophoresis and the autoradiography shows a phosphorylated band at $27000 \mathrm{Mr}$. This gel is representative for three independent experiments using different batches of recombinant p27Kip1 and Erk 2. (B) Phospho amino acid mapping. Phosphorylated p2 $7^{\mathrm{Kip} 1}$ was cut out of the gel and treated as described. Phosphopeptide mapping was done with twodimensional electrophoresis on thin layer chromatographic plates. Non-radioactive phosphorylated amino acids were run as standards in parallel and were detected with ninhydrin. Erk 2 induces serine and threonine, but not tyrosine phosphoryla-

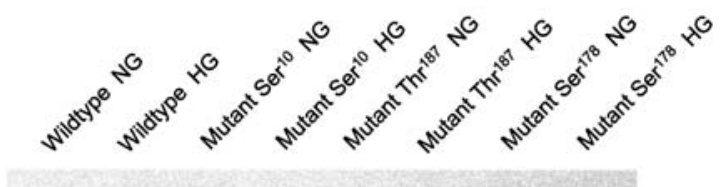

p27Kip1

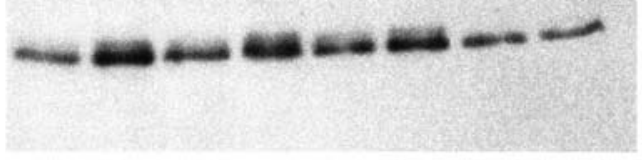

$\beta$-Actin

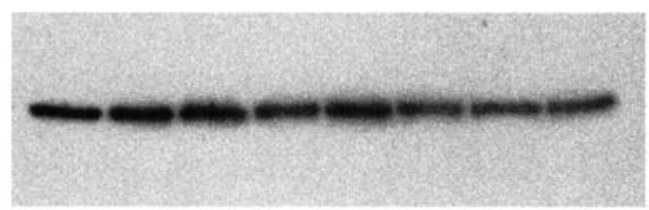

Fig. 4. Western blot for $\mathrm{p} 27^{\mathrm{Kip} 1}$. p2 $27^{\mathrm{Kip} 1} \mathrm{cDNAs}$ with mutations encoding serine ${ }^{10}$, serine ${ }^{178}$, and threonine ${ }^{187}$ were transfected into p27Kip1 - /- mesangial cells and incubated for $24 \mathrm{~h}$ in either normal $(\mathrm{NG})$ or high glucose $(\mathrm{HG})$ with the inducer muristone $(1 \mu \mathrm{g} / \mathrm{ml})$. p27Kip1 $+/+$ wild-type cells, also treated with muristone, served as controls. High glucose stimulates p27Kip1 expression in wild-type as well as p27Kip1 -/_ MCs transfected with serine ${ }^{10}$ and threonine ${ }^{187}$, but not serine ${ }^{178}$ mutants. These blots are representative for three independent experiments

of p27 Kip1 +/+ MCs, but enhances thymidine incorporation in $\mathrm{p} 27^{\mathrm{Kip} 1}-/$ - cells (Fig. 5A). In the current study our results show that reconstitution of p27 Kip1 $-/-$ cells with the serine ${ }^{10}$, and threonine ${ }^{187}$, but not serine ${ }^{178}$ mutants reduced thymidine incorporation in cells grown in high glucose, and thus restored the antiproliferative effect of high glucose medium (Fig. 5A). Similar results were shown using cell cycle analysis. High glucose arrested p27Kip1 +/+ cells and p27 Kip1 $-/-$ reconstituted with serine ${ }^{10}$ and threonine ${ }^{187} \mathrm{mu}-$ tants in the $\mathrm{G}_{1}$ phase of the cell cycle, and this was accompanied by significantly fewer cells progressing into the S-phase. In contrast, in p27Kip1 $-/$ - cells or MCs p27 Kip1 1 - - transfected with the serine ${ }^{178}$ mutant, high glucose-stimulated cell cycle progression (Table 1).

${ }^{3}[\mathrm{H}]$ leucine incorporation, a measure of hypertrophy, was increased by high glucose in $\mathrm{p} 27^{\mathrm{Kip} 1}+/+$ and p27 Kip1 -/- MCs reconstituted with serine ${ }^{10}$ and threo-

tion of p27Kip1. Phosphopeptide mapping was carried out twice with similar results. (C) Phosphorylation of recombinant p27Kip1 by immunoprecipitated Erk 1,2. MCs were incubated for $10 \mathrm{~min}$ or $18 \mathrm{~h}$ in normal glucose (NG) or high glucose (HG) in the presence and absence of the MEK1 inhibitor PD98059. Total Erk 1,2 was immunoprecipitated and the precipitates were tested whether they could phosphorylate p27Kip1 in vitro. Erk 1,2 immunoprecipitated from mesangial cells grown for $18 \mathrm{~h}$, but not for $10 \mathrm{~min}$ in high glucose medium phosphorylate recombinant $\mathrm{p} 27 \mathrm{Kip} 1$. This effect was inhibited by the MEK1 kinase inhibitor. This autoradiography is representative for three independent experiments with qualitatively similar results 
A

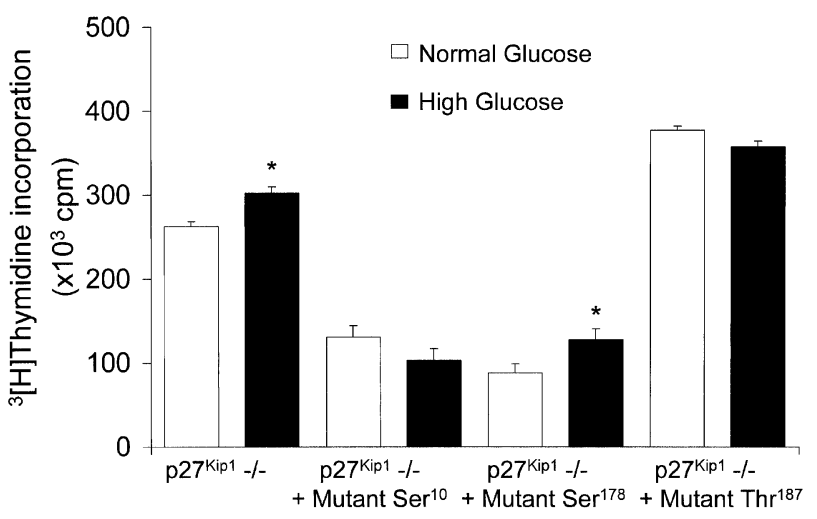

B

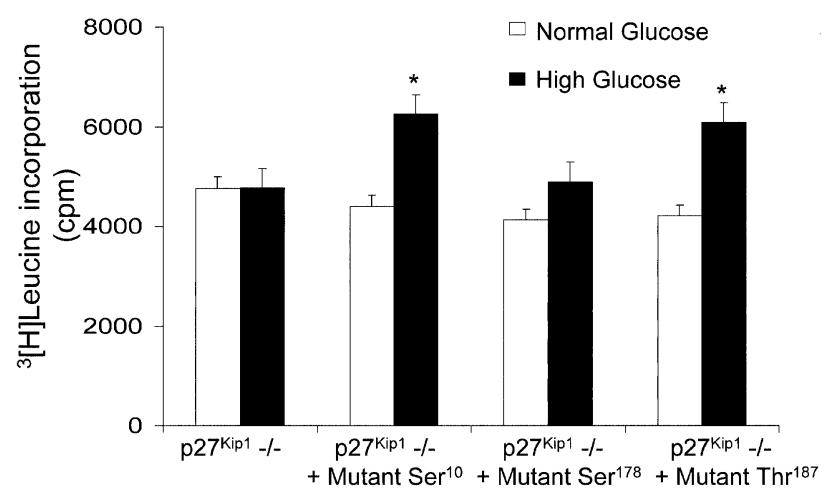

C

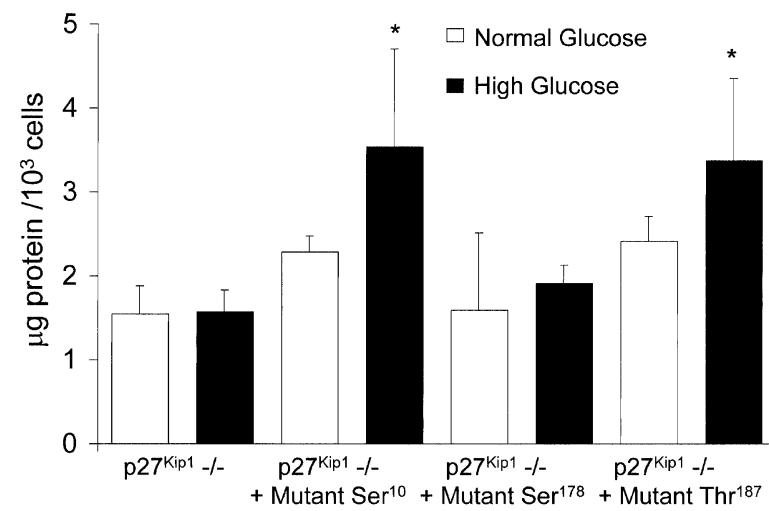

Fig. 5A-C. Functional consequences of p2 $7^{\text {Kip } 1}$ mutations. (A) Proliferation measured by ${ }^{3}[\mathrm{H}]$ thymidine incorporation. High glucose medium stimulates proliferation in p27 ${ }^{\mathrm{Kip} 1}-/-\mathrm{MCs}$ and cells transfected with the serine ${ }^{178}$ mutant. In contrast, high glucose failed to stimulate thymidine incorporation in p27 Kip1 - / cells reconstituted with the serine ${ }^{10}$ or threonine ${ }^{187}$. $^{*} p<0.01$ vs normal glucose, $n=12$. (B) ${ }^{3}[\mathrm{H}]$ leucine incorporation into de novo synthesized proteins. High glucose stimulates de novo protein synthesis in p 27 Kip 1 - - MCs transfected with the serine ${ }^{10}$ or threonine ${ }^{187}$ mutant $\mathrm{p} 27^{\mathrm{Kip} 1}$ expression vectors, but not with the serine ${ }^{178}$ mutant or untransfected p27Kip1 $-/$ - cells. ${ }^{*} p<0.01$ vs high glucose, $n=5$. (C) Measurement of the quotient $\mu \mathrm{g}$ protein/cell number as hypertrophy index. p27 Kip1 $1-$ cells reconstituted with p27 Kip1 $^{2}$ serine ${ }^{10}$ and threonine ${ }^{187}$ mutants develop cellular hypertrophy after exposure to high glucose, but not in p27 Kip1 $-/$ - cells. The p27 Kip1 serine ${ }^{178}$ mutant failed to reconstitute the hypertrophic phenotype. ${ }^{*} p<0.05$ vs high glucose, $n=5$
Table 1. Cell cycle analysis

\begin{tabular}{llll}
\hline Group & $\mathrm{G}_{0} / \mathrm{G}_{1}$ & $\mathrm{~S}$ & $\mathrm{G}_{2} / \mathrm{M}$ \\
\hline p27Kip1 +/+ mesangial cells & & & \\
$\begin{array}{l}\text { in normal glucose } \\
\text { in high glucose }\end{array}$ & $11.86 \%$ & $84.78 \%$ & $3.36 \%$ \\
p27Kip1 _/- mesangial cells & & & \\
in normal glucose & $34.39 \%$ & $65.61 \%$ & $0.00 \%$ \\
in high glucose & $21.56 \%$ & $78.44 \%$ & $0.00 \%$
\end{tabular}

p27 $7^{\text {Kip } 1}-/$ - mesangial cells transfected with serine ${ }^{10}$ mutant

$\begin{array}{llll}\text { in normal glucose } & 35.27 \% & 64.73 \% & 0.00 \% \\ \text { in high glucose } & 38.00 \% & 62.00 \% & 0.00 \%\end{array}$

p27 Kip1 $-/-$ mesangial cells transfected with serine ${ }^{178}$ mutant

$\begin{array}{llll}\text { in normal glucose } & 32.38 \% & 67.62 \% & 0.00 \%\end{array}$

$\begin{array}{llll}\text { in high glucose } & 22.08 \% & 75.72 \% & 2.20 \%\end{array}$

p27 Kip1 $-/-$ mesangial cells transfected with threonine ${ }^{187}$ mutant

\begin{tabular}{llll} 
in normal glucose & $36.02 \%$ & $63.98 \%$ & $0.00 \%$ \\
in high glucose & $31.63 \%$ & $59.75 \%$ & $8.62 \%$ \\
\hline
\end{tabular}

$\begin{array}{llll}\text { in high glucose } & 31.63 \% & 59.75 \% & 8.62 \%\end{array}$

Mean values from two independent experiments

Table 2. Cell Size (measured by Forward Cell Scatter compared with beads of standard size)

\begin{tabular}{ll}
\hline Group & $\begin{array}{l}\text { Cell Diameter } \\
\left(10^{-6} \mathrm{~m}\right)\end{array}$
\end{tabular}

p2 $7^{\text {Kip } 1}+/+$ mesangial cells
in normal glucose
$5.71 \pm 0.16$
in high glucose
$6.49 \pm 0.10^{*}$

p27Kip1 -/- mesangial cells
in normal glucose
$5.27 \pm 0.05$
in high glucose
$4.88 \pm 0.13$

p27 Kip1 $-/$ - mesangial cells transfected with serine ${ }^{10}$ mutant
in normal glucose
$5.28 \pm 0.14$
in high glucose
$6.29 \pm 0.23 *$

p27 Kip1 $-/$ - mesangial cells transfected with serine ${ }^{178}$ mutant
in normal glucose
$5.31 \pm 0.05$
in high glucose
$5.17 \pm 0.09$

p27 Kip1 $-/-$ mesangial cells transfected with threonine ${ }^{187}$ mutant
in normal glucose
$5.60 \pm 0.04$
in high glucose
$6.39 \pm 0.19 *$

Three independent stimulation experiments, $* p<0.05$ vs. normal glucose

nine ${ }^{187}$ mutants. In contrast, ${ }^{3}[\mathrm{H}]$ leucine incorporation was not increased in p27 Kip1 $-/$ - cells or p27 Kip1 $-/$ cells reconstituted with $\mathrm{p} 27^{\mathrm{Kip} 1}$ mutated at serine ${ }^{178}$ (Fig. 5B). In addition, calculating $\mu$ g protein/cell number, a well-established parameter of hypertrophy, also revealed an increase in p27+/+ and p27Kip1 $-/$ - cells 
reconstituted with serine ${ }^{10}$ and threonine ${ }^{187}$ mutants after exposure to high glucose, but not in p27Kip1 -/ cells transfected with at serine ${ }^{178}$. Again, the serine ${ }^{178}$ mutant failed to reconstitute the hypertrophic phenotype (Fig. 5C). Finally, we also measured cell size using forward cell scatter. In contrast to p $27 \mathrm{Kip} 1-/$ - cells that slightly reduced their individual size, high glucose increased cell size in p27Kip1 +/+ MCs. Reconstitution of p27Kip1 (-/-) MCs with serine ${ }^{10}$ and threonine ${ }^{187}$ mutants restored the high glucose-induced increase in cell size in p27Kip1 - /- cells. However, the p27 Kip1 serine ${ }^{178}$ mutant was without effect (Table 2). These results show that the hypertrophic and anti-proliferative phenotype induced by high glucose requires phosphorylation of serine ${ }^{178}$ of p27Kip1.

\section{Discussion}

High glucose induces $G_{1}$ phase arrest of cultured mesangial cells with the concomitant development of hypertrophy. We have shown that expression of the CDK-inhibitors $\mathrm{p} 27^{\mathrm{Kip} 1}$ and $\mathrm{p} 21^{\mathrm{Cip} 1}$ are increased by high glucose in mesangial cells in vivo and in vitro $[12,19,20,21]$. Studies in $\mathrm{p} 27^{\mathrm{Kip} 1}-/-$ and $\mathrm{p} 21^{\mathrm{Cip} 1}-/-$ MCs revealed that these CDK-inhibitors are essential for high glucose-mediated hypertrophy of mesangial cells. Furthermore, treatment of BBdp rats, a model of autoimmune diabetes mellitus Type 1, with angiotensin-converting enzyme inhibitors reduced the glomerular expression of $\mathrm{p} 27^{\mathrm{Kip} 1}$ and this was accompanied by a decrease in renal hypertrophy [20]. In addition, p2 $1^{\text {Cip } 1 ~-/-~[21] ~ a n d ~ p 27 ~ K i p 1 ~-/-~[22] ~ m i c e ~ a r e ~ p r o t e c t-~}$ ed to some extent of the development of morphological and functional changes of diabetic nephropathy. These studies clearly show a pivotal role for these specific CDK-inhibitors in the development of glomerular hypertrophy of diabetes mellitus.

The observation that high glucose stimulates p27 Kip1 protein expression in MCs without changes in mRNA abundance suggests a probable post-transcriptional regulation of $\mathrm{p} 2 \mathrm{~K}^{\mathrm{Kip} 1}[10,12,19,23]$. Since MAP kinases are activated during diabetic nephropathy, and renal hypertrophy is dependent on MAP kinase activation in other situations $[13,14]$, in the current study we studied the potential relationship between Erk 1,2 activation and regulation of p27Kip1. Similar to previous studies, we showed Erk 1,2 phosphorylation by high glucose in cultured mesangial cells $[13,14,24,25,26]$. The molecular mechanisms underlying high glucose-induced activation of MAP kinases have been recently delineated $[27,28]$. Superoxide formation induced by high glucose-mediated activation of the mitochondrial electron-transport chain plays a pivotal role [28]. Excess superoxide inhibits the glycolytic enzyme GAPDH, thereby diverting metabolites from glycolysis into the protein kinase C (PKC) pathway $[27,28]$. In turn, stimulation of PKC activates Erk 1,2, partly by inhibiting expression of MAPK phosphatase-1 (MKP-1; 29).

In this study we showed that inhibition of high glucose-induced Erk 1,2 phosphorylation prevented mesangial cell hypertrophy. Accordingly, we asked if Erk 1,2 directly phosphorylates $\mathrm{p} 27^{\mathrm{Kip} 1}$. Our results showed that active Erk 2 directly phosphorylated recombinant p27Kip1 in vitro. Furthermore, Erk 1,2 immunoprecipitated from cells grown in high glucose phosphorylated recombinant $\mathrm{p} 27^{\mathrm{Kip} 1}$, which did not occur when Erk 1,2 was immunoprecipitated from cells grown in medium with normal glucose. Further proof that Erk 1,2 directly phosphorylates $\mathrm{p} 27^{\mathrm{Kip} 1}$ was provided by phospho amino acid mapping. We then mutated the three MAP kinase phosphorylation sites of $\mathrm{p} 27^{\mathrm{Kip} 1}$, and showed that changing the serine ${ }^{178}$ to alanine prevented glucose-induced p27Kip1 expression. Finally, functional studies showed that serine ${ }^{178}$ mutation, in contrast to wild-type or serine ${ }^{10}$, and threonine ${ }^{187}$ failed to promote high glucose-induced hypertrophy of mesangial cells, showing the role for specific protein phosphorylation in mediating the effect of glucose on mesangial cell growth.

p27 Kip1 expression is thought to be regulated by both translational and post-translational mechanisms, and only under very limited circumstances at the level of transcription [23, 30]. The ubiquitin-proteasome pathway of protein degradation is a major factor in regulating p27 Kip1 abundance [30]. This is a complex process initiated by $\mathrm{CDK} 2 /$ cyclin $\mathrm{E}$ activated phosphorylation of the threonine ${ }^{187}$ residue $[31,32]$. A multienzyme protein, SCFSkp2, complexes with ubiquitin ligase, then binds to phosphorylated p27Kip1 [33]. A critical protein in this complex is Skp2 this assembles the other members of the protein SCFSkp2 complex through the F-box motif, while its C-terminal region binds to the phosphorylated threonine ${ }^{187}$ of the substrate p27Kip1 [33]. It has been recently discovered that the CDK protein Cks1 is an essential accessory factor for the SCFSkp2 complex [35]. Cks1 apparently promotes allosteric changes of Skp2 so that SCFSkp2 could bind to the phosphorylated threonine ${ }^{187}$ of p27Kip1. In addition, Cks1 might also facilitate the recruitment of phosphorylated p27Kip1 to the SCFSkp2 complex and stabilizes their interaction [35]. Recent studies suggest that $\mathrm{p} 27^{\mathrm{Kip} 1}$ degradation is differentially regulated in $G_{0} / G_{1}$ and $S / G_{2}$ transitions $[37,38]$. One study produced mice expressing $\mathrm{p} 27^{\mathrm{Kip} 1}$ in which threonine ${ }^{187}$ is mutated to alanine. [38] Although these mice were unable to down-regulate $\mathrm{p} 27 \mathrm{Kip} 1$ in the $\mathrm{S} / \mathrm{G}_{2}$ phase transition because Skp2 can not bind to p27 Kip1, p27 Kip1 degradation in $G_{1}$ was unaffected [38]. Thus, this $G_{1}$ phase proteolytic pathway for $\mathrm{p} 27^{\mathrm{Kip} 1}$ also required Skp2 binding to $\mathrm{p} 27^{\mathrm{Kip} 1}$ but independent of threonine ${ }^{187}$ phosphorylation.

The effect of MAP kinase activation on expression of CDK inhibitors varies depending on cell type, stimulus and duration of activation. In fibroblasts, activa- 
tion of MAP kinases leads to an increase in p27Kip1 degradation that is independent of phosphorylation by CDK2/cyclin E $[39,40,41]$. In contrast, a more delayed and prolonged activation of MAP kinases, for example induced in PC12 cells and fibroblasts by nerve growth factor, leads to cell cycle arrest [42]. This effect is associated by an Erk 1,2-dependent increase in the expression of CDK-inhibitors including p27Kip1 [42]. However, the mechanism of this MAP kinase mediated increase in $\mathrm{p} 27^{\mathrm{Kip} 1}$ expression has been not investigated.

In agreement with our findings, it has been previously reported that Erk 1,2 phosphorylates p27 Kip1 in vivo and in vitro [39, 43]. Similar to our experiments, others mutated the three serine/threonine kinase consensus sites of p27Kip1 [43]. They found that phosphorylation of serine ${ }^{10}$ accounted for $70 \%$ of the total $\mathrm{p} 27^{\mathrm{Kip} 1}$ phosphorylation [43]. All three p27Kip1 mutants inhibited the kinase activity of CDK2/cyclin E or CDK4/cyclin D2 to a similar extent [43]. The same study provides evidence that phosphorylation of serine 10 increased the half-life of p27Kip1 about two-fold by promoting binding to CRM1, a carrier protein for nuclear transport, and facilitating cytoplasmatic export from the nucleus [44]. In this study, nuclear export controlled by serine ${ }^{10}$ phosphorylation was necessary for $\mathrm{p} 27^{\mathrm{Kip} 1}$ down-regulation and mitogen-induced $\mathrm{G}_{0} / \mathrm{G}_{1}$ transition [44]. Others have reported a similar mechanism of serine ${ }^{10}$ phosphorylation in nuclear export and cell cycle progression, but found no evidence that this phosphorylation increased p27 Kip1 expression because serine ${ }^{10}$ mutants were efficiently recognized by Skp2 [45]. The effect of serine ${ }^{178}$ phosphorylation on $\mathrm{p} 27^{\mathrm{Kip} 1}$ stability was not investigated in these studies $[44,45]$.

However, since high glucose mediates cell cycle arrest with an increase in p27Kip1 $[10,12]$, it is very unlikely that phosphorylation of serine ${ }^{10}$ which would induce $\mathrm{G}_{0} / \mathrm{G}_{1}$-phase progression plays a role in hypertrophy of mesangial cells. Moreover, although one study reported that Erk 1,2 phosphorylates p27Kip1 at serine $^{10}$ and serine ${ }^{178}$ in vitro, serine ${ }^{10}$ was not phosphorylated in vivo [43]. This could very well explain our observation that mutation of serine ${ }^{178}$ attenuates the high glucose induced increase in $\mathrm{p} 27^{\mathrm{Kip} 1}$ and hypertrophy. Assuming that high glucose-induced activation of Erk 1,2 only phosphorylates serine ${ }^{178}$ in vivo, it is tempting to assume that phosphorylation of this amino acid might counteract nuclear export transport as mediated by serine ${ }^{10}$ phosphorylation. As a consequence, less p27Kip1 translocates into the cytoplasm subjected to degradation after binding to Skp2. Alternatively, phosphorylation of serine ${ }^{178}$ could directly influence binding of $\mathrm{p} 27^{\mathrm{Kip} 1}$ to the $\mathrm{SCF}{ }^{\mathrm{Skp}}{ }^{2} \mathrm{com}$ plex by modulating the three dimensional structure of the complex. Further studies are necessary to test these hypothesis. Finally, we have recently observed that under certain conditions cell cycle arrest and hypertrophy are independently regulated by CDK-inhibi- tors [46]. Transforming growth factor- $\beta$ still induces $\mathrm{G}_{1}$ phase arrest in $\mathrm{p} 27_{\mathrm{Kip} 1}-\mathrm{/}$ - MCs, but not hypertrophy compared to wild-type cells [46]. This observation suggests that $\mathrm{p} 27^{\mathrm{Kip} 1}$ can induce hypertrophy by other, currently unknown mechanisms than cell cycle arrest [46]. Perhaps, phosphorylation of serine ${ }^{178}$ of p27Kip1 could be important for this cell cycle independent pathway of hypertrophy. However, in our study inhibition of proliferation, hypertrophy, and p27Kip1 expression was closely associated making this a cell cycle independent mechanism of hypertrophy mediated by $\mathrm{p} 27^{\mathrm{Kip} 1}$ less likely.

Acknowledgements. This study was supported by grants from the Deutsche Forschungsgemeinschaft (Wo 460/2-4, 2-5, 121), and by Public Health Service grants (DK34198, DK52121, DK51096, DK56799) and a George M O'Brien Kidney Center Grant (DK47659). Parts of this study were presented at the annual meeting of the American Society of Nephrology (October 10-17, 2001, San Francisco, USA) and have been published in abstract form (J Am Soc Nephrol 12:623A, 2001). We thank R. Schroeder for excellent technical help, T. Hannken, Ph.D., for her initial help with establishing the kinase assays, and Professor Dr. M. Eilers (Institute for Molecular Biology and Tumor Research, University of Marburg, Germany) for providing the histidine-tagged p27Kip1 cDNA.

\section{References}

1. Bak M, Thomsen K, Christiansen T, Flyvbjerg A (2000) Renal enlargement precedes renal hyperfiltration in early experimental diabetes in rats. J Am Soc Nephrol 11:12871292

2. Drummond K, Mauer M (2002) The early natural history of nephropathy in type 1 diabetes. II. Early renal structural changes in type 1 diabetes. Diabetes 51:1580-1587

3. Baumgartl HJ, Sigl G, Banholzer P, Halsbeck M, Standl E (1998) On the prognosis of IDDM patients with larger kidneys. Nephrol Dial Transplant 13:630-634

4. Fogo A, Ichikawa I (1991) Evidence for a pathogenic linkage between glomerular hypertrophy and sclerosis. Am J Kidney Dis 17:666-669

5. Wolf G, Ziyadeh FN (1999) Molecular mechanisms of diabetic renal hypertrophy. Kidney Int 56:393-405

6. Wolf G, Sharma K, Chen Y, Ericksen M, Ziyadeh FN (1992) High glucose-induced proliferation in mesangial cells is reversed by autocrine TGF- $\beta$. Kidney Int 42:647656

7. Huang HC, Preisig PA (2000). $\mathrm{G}_{1}$ kinases and transforming growth factor- $\beta$ signaling are associated with a growth pattern switch in diabetes-induced renal growth. Kidney Int 58:162-172

8. Cosio FG (1995) Effects of high glucose concentrations on human mesangial cell proliferation. J Am Soc Nephrol 5:1600-1609

9. Kuan CJ, Al-Douahji M, Shankland SJ (1998) The cyclin kinase inhibitor $\mathrm{p} 21^{\mathrm{WAF} 1, \mathrm{CIP} 1}$ is increased in experimental diabetic nephropathy: potential role in glomerular hypertrophy. J Am Soc Nephrol 9:986-993

10. Wolf G, Schroeder R, Ziyadeh FN, Thaiss F, Zahner G, Stahl RAK (1997) High glucose stimulates expression of p27Kip1 in cultured mouse mesangial cells: relationship to hypertrophy. Am J Physiol 273:348-356 
11. Wolf G, Schroeder R, Thaiss F, Ziyadeh FN, Helmchen U, Stahl RAK (1998) Glomerular expression of p27 Kip1 in diabetic $d b / d b$ mouse: role of hyperglycemia. Kidney Int 53:869-879

12. Wolf G, Schroeder R, Zahner G, Stahl, RAK, Shankland SJ (2001) High glucose-induced hypertrophy of mesangial cells requires $\mathrm{p} 27 \mathrm{Kip} 1$, an inhibitor of cyclin-dependent kinases. Am J Pathol 158:1091-1100

13. Wolf G, Haberstroh U, Neilson EG (1992) Angiotensin II stimulates the proliferation and biosynthesis of type I collagen in cultured murine mesangial cells. Am J Pathol 140:95-107

14. Ernest S, Bello-Reus E (1996) Xenobiotic transport differences in mouse mesangial cell clones mdr1 and mdr3. Am J Physiol 270 (Cell Physiol 39):C910-C919

15. Isono M, Iglesias-de la Cruz MC, Chen S, Hong SW, Ziyadeh FN (2000) Extracellular signal-regulated kinase mediates stimulation of TGF- $\beta 1$ and matrix by high glucose in mesangial cells. J Am Soc Nephrol 11:2222-2230

16. Awazu M, Ishikura K, Hida M, Hoshiya M (1999) Mechanisms of mitogen-activated protein kinase activation in experimental diabetes. J Am Soc Nephrol 10:738-745

17. Müller D, Thieke K, Bürgin A, Dickmanns A, Eilers M (2000) Cyclin E-mediated elimination of p27 requires its interaction with the nuclear pore-associated protein mNPAP60. EMBO J 1119:2168-2180

18. Boyle WJ, van der Geer P, Hunter T (1991) Phosphopeptide mapping and phosphoamino acid analysis by two-dimensional separation on thin-layer cellulose plates. Methods Enzymol 201:110-149

19. Hannken T, Schroeder R, Zahner G, Stahl RAK, Wolf G (2000) Reactive oxygen species stimulate p44/42 MAP kinase and induce p27Kip1: role in angiotensin II-mediated hypertrophy of proximal tubular cells. J Am Soc Nephrol 11:1387-1397

20. Wolf G, Wenzel U, Ziyadeh, FN, Stahl RAK (1999) ACEinhibitor treatment reduces glomerular p16 ${ }^{\mathrm{INK} 4}$ and p27Kip1 expression in diabetic BBdp rats. Diabetologia 42:1425-1432

21. Al-Douahji M, Brugarolas J, Brown PA, Stehman-Breen CO, Alpers CE, Shankland SJ (1999) The cyclin kinase inhibitor $\mathrm{p} 21^{\mathrm{WAF} / \mathrm{CIP} 1}$ is required for glomerular hypertrophy in experimental diabetic hypertrophy. Kidney Int 56:16911699

22. Awazu M, Omori S, Ishikura K, Hida M, Fujita H (2003) The lack of cyclin kinase inhibitor p27 Kip1 ameliorates progression of diabetic nephropathy. J Am Soc Nephrol 14: 699-708

23. Alessandrini A, Chiaur DS, Pagano M (1997) Regulation of the cyclin-dependent kinase inhibitor p27 by degradation and phosphorylation. Leukemia 11:342-345

24. Wilkinson MG, Millar JBA (2000) Control of the eukaryotic cell cycle by MAP kinase signaling pathways. FASEB J 14:2147-2157

25. Tian W, Zhang Z, Cohen DM (2000) MAPK signaling and the kidney. Am J Physiol Renal Physiol 279:F593-F604

26. Ingram AJ, Ly H, Thai K, Kang MJ, Scholey JW (1999) Mesangial cell signaling cascades in response to mechanical strain and glucose. Kidney Int 56:1721-1728

27. Brownlee M (2001) Biochemistry and molecular cell biology of diabetic complications. Nature 414:813-820

28. Nishikawa T, Edelstein D, Du XL et al. (2000) Normalizing mitochondrial superoxide production blocks three pathways of hyperglycaemic damage. Nature 404:787-790

29. Jacobs D, Glossip D, Xing H, Muslin AJ, Kornfeld K (1999) Multiple docking sites on substrate proteins form a modular system that mediates recognition by ERK MAP kinase. Genes Dev 13:163-175
30. Pagano M, Tam SW, Theodoras AM et al. (1995) Role of the ubiquitin-proteasome pathway in regulating abundance of the cyclin-dependent kinase inhibitor p27. Science 269: 682-685

31. Sheaff RJ, Groudine M, Gordon M, Roberts JM, Clurman BE (1997) Cyclin E-CDK2 is a regulator of p27Kip1. Genes Dev 11:1464-1478

32. Vlach J, Hennecke S, Amati B (1997) Phosphorylationdependent degradation of the cyclin-dependent kinase inhibitor p27Kip1. EMBO J 16:5334-5344

33. Tsvetkov LM, Yeh KH, Lee SJ, Sun H, Zhang H (1999) p27Kip1 ubiquitination and degradation is regulated by the SCFSkp2 complex through phosphorylated Thr187 in p27. Curr Biol 9:661-664

34. Nakayama K, Nagahama H, Minamishima YA et al. (2000) Targeted disruption of $S k p 2$ results in accumulation of cyclin E and p27Kip1, polyploidy and centrosome overduplication. EMBO J 19:2069-2081

35. Spruck C, Strohmaier H, Watson M et al. (2001) A CDKindependent function of Cks1: targeting of SCFSkp2 to the CDK inhibitor p27Kip1. Mol Cell 7:639-650

36. Hara T, Kamura T, Nakayama K, Oshikawa K, Hatakeyama $\mathrm{S}$, Nakayama KI (2001) Degradation of p27Kip1 at the $\mathrm{G}_{0^{-}}$ $\mathrm{G}_{1}$ transition mediated by a Skp2-independent ubiquitination pathway. J Biol Chem 276:48937-48943

37. Shirane M, Harumiya Y, Ishida N et al. (1999) Down-regulation of $\mathrm{p} 27^{\mathrm{Kip} 1}$ by two mechanisms, ubiquitin-mediated degradation and proteolytic processing. J Biol Chem 274: 13886-13893

38. Malek NP, Sundberg H, McGrew S, Nakayama K, Kyriakidis TR, Roberts JM (2001) A mouse knock-in model exposes sequential proteolytic pathways that regulate $\mathrm{p} 27^{\mathrm{Kip} 1}$ in G1 and S phase. Nature 413:323-327

39. Kawada M, Yamagoe S, Murakami Y, Suzuki K, Mizuno S, Uehara Y (1997) Induction of p27Kip1 degradation and anchorage independence by Ras through the MAP kinase signaling pathway. Oncogene 15:629-637

40. Delmas C, Manenti S, Boudjelal A, Peyssonnaux C, Eychène A, Darbon JM (2001) The p42/p44 mitogen-activated protein kinase activation triggers $\mathrm{p} 27 \mathrm{Kip} 1$ degradation independently of CDK2/cyclin E in NIH 3 T3 cells. J Biol Chem 276:34958-34965

41. Cheng M, Sexl V, Sherr CJ, Roussel MF (1998) Assembly of cyclin D-dependent kinase and titration of p27Kip1 regulated by mitogen-activated protein kinases kinase (MEK1). Proc Natl Acad Sci USA 95:1091-1096

42. Pumiglia KM, Decker SJ (1997) Cell cycle arrest mediated by the $\mathrm{MEK} / \mathrm{mitogen}$-activated protein kinase pathway. Proc Natl Acad Sci USA 94:448-452

43. Ishida N, Kitagawa M, Hatakeyama S, Nakayama KI (2000) Phosphorylation at serine 10, a major phosphorylation site of $\mathrm{p} 27_{\mathrm{Kip} 1}$, increases its protein stability. J Biol Chem 275:25146-25154

44. Ishida N, Hara T, Kamura T, Yoshida M, Nakayama K, Nakayama KI (2002) Phosphorylation of p27Kip1 on serine 10 is required for its binding to CRM1 and nuclear export. J Biol Chem 277:14355-14358

45. Rodier G, Montagnoli A, Di Marcotullio L et al. (2001) p27 cytoplasmic localization is regulated by phosphorylation on Ser10 and is not a prerequisite for its proteolysis. EMBO J 20:6672-6682

46. Monkawa T, Hiromura K, Wolf G, Shankland SJ (2002) The hypertrophic effect of transforming growth factor- $\beta$ is reduced in the absence of cyclin-dependent kinase-inhibitors p21 and p27. J Am Soc Nephrol 13:1172-1178 